\title{
Histology and symplasmic tracer distribution during development of barley androgenic embryos
}

\author{
Justyna Wrobel · Peter W. Barlow • \\ Karolina Gorka · Danuta Nabialkowska • \\ Ewa U. Kurczynska
}

Received: 15 June 2010/Accepted: 23 December 2010/Published online: 12 January 2011

(C) The Author(s) 2011. This article is published with open access at Springerlink.com

\begin{abstract}
The present study concerns three aspects of barley androgenesis: (1) the morphology and histology of the embryos during their development, (2) the time course of fluorescent symplasmic tracers' distribution, and (3) the correlation between symplasmic communication and cell differentiation. The results indicate that barley embryos, which are developing via an androgenic pathway, resemble their zygotic counterparts with respect to their developmental stages, morphology and histology. Analysis of the distribution of the symplasmic tracers, HPTS, and uncaged fluorescein indicates the symplasmic isolation of (1) the protodermis from the underlying cells of the late globular stage onwards, and (2) the embryonic organs at the mature stage of development.
\end{abstract}

Keywords Androgenic embryo - Barley · CMNB-caged fluorescein - Embryogenesis . HPTSA · Symplasmic domains

Electronic supplementary material The online version of this article (doi:10.1007/s00425-010-1345-0) contains supplementary material, which is available to authorized users.

J. Wrobel $(\bowtie) \cdot$ K. Gorka · E. U. Kurczynska

Laboratory of Cell Biology, University of Silesia,

ul. Jagiellońska 28, 40-032 Katowice, Poland

e-mail: justyna.wrobel@us.edu.pl

E. U. Kurczynska

e-mail: euk@us.edu.pl

D. Nabialkowska

Department of Genetics, University of Silesia,

ul. Jagiellońska 28, 40-032 Katowice, Poland

P. W. Barlow

School of Biological Sciences, University of Bristol,

Woodland Road, Bristol BS8 1UG, UK

\begin{abstract}
Abbreviations
CMNB 5-Carboxymethoxy-2-nitrobenzyl

SEL Size exclusion limit

HPTS 8-Hydroxypyrene-1,3,6-trisulfonic acid, trisodium salt
\end{abstract}

HPTSA Acetic derivative of HPTS

\section{Introduction}

Under in vitro conditions, plant microspores can develop androgenic embryos via a process called microspore embryogenesis, as was first shown for Datura microspores by Guha and Maheshwari (1966). More recently, androgenic embryos have been obtained from many different plants, both monocots (Testillano et al. 2002; Konieczny et al. 2003) and dicots (Bugarova and Pret'ova 1996; Chanana et al. 2005).

Barley androgenesis is important for plant breeding as it allows production of homozygous plants and their genetic analysis, and efforts have been made for improving the efficiency by which barley plants with desirable traits can be obtained using the androgenic pathway (Davies and Morton 1998; Wang et al. 2000; Maraschin et al. 2003). These improvements have been helped by appropriate molecular analysis (Maraschin et al. 2003; 2005a, b). However, little work has been done to analyze the morphology, histology, and cytology of androgenic embryos, topics which may be considered as major prerequisites for a correct understanding of embryogenesis and its underlying molecular, biochemical and physiological parameters.

An interesting aspect of barley androgenesis is the possibility that symplasmic domains emerge during the 
development of the embryo. For example, during zygotic embryogenesis of Arabidopsis thaliana symplasmic communication between the embryo cells changes (Gisel et al. 1999; Roberts and Oparka 2003; Kim and Zambryski 2005). It has been postulated that diminished symplasmic communication between embryo cells and the formation of symplasmic domains is involved in cellular differentiation (Duckett et al. 1994; Gisel et al. 1999; Kim and Zambryski 2005), and that these domains may lead to the partitioning of the embryo into distinct areas of histo- and organogenesis. In vitro androgenesis proves to be a convenient model system to study such aspects of embryogenesis because the stages of embryo development can be easily monitored.

The aim of the present study, therefore, was to (1) describe the morphology and histology of androgenic barley embryos, (2) analyze the distribution of symplasmic tracers within the embryos at different stages of development, and (3) answer the question whether there is any correlation between changes in symplasmic communication of embryo cells and cell differentiation.

\section{Materials and methods}

\section{Materials and culture condition}

Androgenesis was produced in anther culture of Hordeum vulgare L. cv. Morex. Donor plants of $H$. vulgare L. (kindly provided by Department of Plant Agriculture, Guelph, Canada) were grown in a phytotron at $18{ }^{\circ} \mathrm{C} / 14{ }^{\circ} \mathrm{C}$ day/night with $16 \mathrm{~h}$ photoperiod. Spikes were collected when microspores were at their early-mid to mid-late stages of development (Szarejko 2003). Tillers containing spikes at the appropriate stage were surface sterilized by spraying with $70 \%$ ethanol and spikes were then transferred to a 12-cm diameter Petri dish for a cold pre-treatment of 21 days at $4{ }^{\circ} \mathrm{C}$. Anthers were then excised with forceps and groups of 20-30 anthers were placed in 5-cm diameter Petri dishes, each containing $3 \mathrm{~mL}$ of semi-liquid induction medium BAC3 (Szarejko 2003). The dishes were sealed with parafilm and placed in an incubator in darkness at $27^{\circ} \mathrm{C}$ for 3-4 weeks.

Sample processing for stereo- and bright field microscopy

The cultured androgenic embryos in different stages of development were taken for histological analysis. Samples were fixed in $2.5 \%$ glutaraldehyde in $0.2 \mathrm{M}$ phosphate buffer, $\mathrm{pH}$ 7.4, dehydrated in an ethanol series and embedded in Steedman's wax according to the procedure of Vitha et al. (1997). After polymerization, the samples were cut into a series of sections (10 $\mu \mathrm{m}$ thick) and stained with periodic acid Schiff reagent (PAS) + toluidine blue. Sections were examined under an Olympus BX42 microscope (Olympus) equipped with a CCD photo camera. Sections of at least 10 embryos were studied at every developmental stage of androgenesis.

Measurement of zygotic and androgenic embryos

Zygotic embryos were excised from $H$. vulgare L. cv. Morex seeds, which were treated with distilled, aerated water for several hours at room temperature. To determine their size, 50 zygotic and androgenic embryos, both at the mature stage of development, were measured under a stereomicroscope (Nikon SMZ 1500) and the average dimensions were calculated.

Analysis of symplasmic tracers distribution in androgenic embryos

Distribution of fluorescent probe of symplasmic connection within the androgenic embryos was monitored using CMNBcaged fluorescein [fluorescein bis-(5-carboxymethoxy-2nitrobenzyl) ether, dipotassium salt] (Molecular Probes, cat. no. F7103) according to the method of Martens et al. (2004). Briefly, CMNB-caged fluorescein was dissolved in $1 \mathrm{~mL}$ of $0.2 \%$ dimethyl sulfoxide (a stock solution). The stock solution of CMNB-caged fluorescein was dissolved in demineralized water to final concentration of $0.01 \%$. Embryos were treated for $1 \mathrm{~h}$ in darkness with $0.01 \%$ CMNB-caged fluorescein. Afterwards, embryos were washed in demineralized water, placed upon a microscopic slide and covered with a cover glass. Uncaging of CMNBcaged fluorescein was performed using a laser scanning confocal microscope (LSM 510; Zeiss) which was built onto an Axiovert $200 \mathrm{M}$ fluorescence microscope (Zeiss) as follows: the selected part of the embryo was illuminated with UV light (using a UV + Vis lamp and a BP365/12 excitation filter) for 5-30 s. Such a procedure released uncaged fluorescein within the protodermis and 2-3 cell layers of underlying tissue (thus the analysis of symplasmic connection between embryo cells with the use of the uncaged fluorescein took place along the longitudinal axis of the embryo). The region of illumination was restricted by a field aperture, allowing passage of UV light to a precisely delineated region. Uncaged fluorescein ( $\mathrm{MW}=$ $332 \mathrm{Da}$ ) was excited by 488 -nm light produced by an argon laser. Detection of the fluorochrome was performed using a filter set consisting of an HFT UV/488/543/633 beam splitter in combination with an NFT 545 beam splitter and a BP 500-530 band-pass filter. Under such conditions the emission of uncaged fluorescein is between 510 and $530 \mathrm{~nm}$, producing a green-yellow fluorescence. 
Uncaging of the fluorescein was performed in different regions of the embryos and at different stages of their development. At the globular stage, the area of uncaging was performed in the centre of the embryo, and at the transitional stage uncaging was done separately in the apical and basal embryonic poles. At the coleoptile and mature stage, uncaging was performed separately in a scutellum, a coleoptile, a SAM (shoot apical meristem) and a coleorhiza. The spatial pattern of uncaged fluorescein distribution was monitored and photographed immediately after uncaging and at 10-min intervals during the following hour. Symplasmic communication between the radicle and other embryo organs was examined indirectly: the fluorochrome was released in the coleoptile, the scutellum or the coleorhiza, and the fluorochrome movement (in the direction of the radicle) was monitored as mentioned above.

Another symplasmic movement tracer used was HPTSA (8-acetoxypyrene-1,3,6-trisulfonic acid, trisodium salt) (Sigma-Aldrich, Cat. No. 00879). HPTSA solution was made by dissolving $5 \mathrm{mg}$ of the fluorochrome in $1 \mathrm{~mL}$ of $1 / 2$ MS medium (Murashige and Skoog 1962). HPTSA is a membrane-permeable, non-fluorescent acetic derivative of HPTS $(\mathrm{MW}=520 \mathrm{Da})$. After entering the cell cytoplasm, the acetic groups of the fluorochrome are cleaved by intracellular nonspecific esterases and the membraneimpermeable, fluorescent form of the fluorochrome is released (Wright and Oparka 1996). The embryos were immersed in the HPTSA solution for 15-60 min. The length of incubation time depended on the stage of embryo development and was determined by preliminary experiments. In these experiments, embryos (at different stages of development) were incubated in the fluorochrome solution for 5, 10, 15, 30, 45, 60, 90, 120 and $180 \mathrm{~min}$. After each period of time, the distribution of HPTS (within embryos) was checked (analysis was performed only on these embryos in which the fluorochrome was not detected in the cell walls). The incubation time was the shortest period in which the pattern of fluorochrome distribution did not change. On the basis of preliminary experiments, globular embryos were incubated in the solution for $15 \mathrm{~min}$, embryos at the transitional stages for $30 \mathrm{~min}$, and embryos at coleoptilar and mature stages for $1 \mathrm{~h}$. After the incubation, embryos were washed at least five times with $1 / 2 \mathrm{MS}$ medium. Distributions of HPTS were analyzed using a laser scanning confocal microscope (LSM 510; Zeiss). Embryos were viewed using a 5, 10 or $20 \times$ long-workingdistance objective (Plan-Neofluar $5 \times$, Plan-Neofluar $10 \times$, LD-Achroplan $20 \times$ ). Conditions used for excitation and detection of the HPTS $(510-520 \mathrm{~nm})$ were identical to those described for uncaged fluorescein. Optical sections through embryos were made to allow analysis of HPTS distribution within them.
CMNB-caged fluorescein was used as a symplasmic tracer to analyze diffusive cell-to-cell communication between different embryo organs, whereas HPTSA was used to analyze this communication between different embryonic tissues. For each developmental stage and for each tested fluorochrome at least 20 androgenic embryos were analyzed. Viability of the embryos was checked by staining with $0.05 \%$ Evans Blue for 10-15 min. Dead embryos were excluded from this study.

\section{Results}

General morphology of androgenic embryos

The developmental stages of androgenesis were recorded as globular, transitional, coleoptilar and mature. According to Zimmermann and Werr (2005), when outgrowth of the scutellum was evident, such a stage was designated as transitional; when the coleoptile was visible, such a stage was named as coleoptilar.

The average length of androgenic embryos was $1.45 \mathrm{~mm}(\mathrm{SD} \pm 0.39)$ and for zygotic counterparts (in the similar-mature - stage of development) average length was $3.51 \mathrm{~mm}(\mathrm{SD} \pm 0.17)$.

In the culture of androgenic material, structures were frequently seen which resembled embryos but which, on closer examination, proved not to be true embryos. Analyses of serial longitudinal sections revealed them to contain unorganized masses of cells with vessel members inside. Protodermal and dividing cells were lacking (data not shown).

Such histological analysis of structures developed in the culture seemed to be essential for proper interpretation of received results concerning fluorochromes distribution within the androgenic embryos.

Histology of androgenic embryos in different stages of development

At the early globular stage, the embryo consisted of a welldeveloped protodermis (Fig. 1a) under which were several layers of cells with large vacuoles and with many starch grains. At this early stage of development, polarization of the embryo was visible in the form of 3-4 layers of cells which were organized in defined radial files and which probably would have developed into the coleorhiza (Fig. 1a).

At the more advanced globular stage, 4-5 layers of the ground meristem cells were present under the protodermis (Fig. 1b). Deep in the embryo (20-30 $\mu \mathrm{m}$ from the embryo surface, depending on embryo size), a zone of dividing 

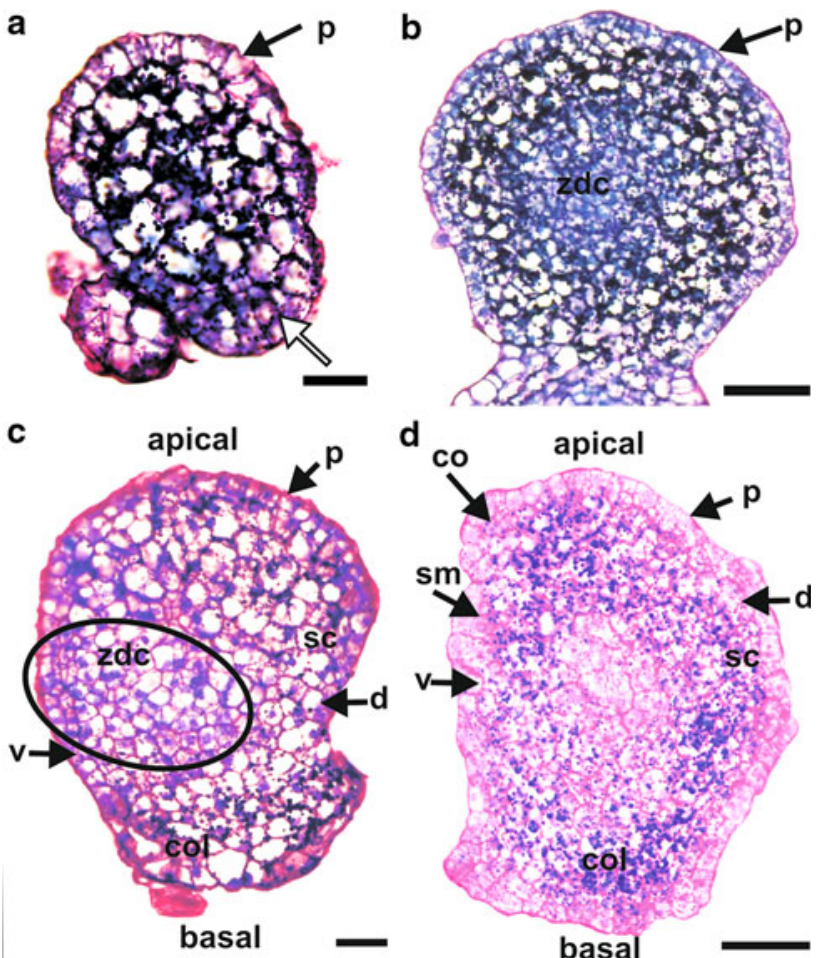

Fig. 1 Histology of barley androgenic embryos at different stages of development. a Except for their basal part (white arrow), embryos at the early globular stage possessed one layer of protodermal cells. Underneath the protodermis, cells with large vacuoles and many starch grains were visible. b At a later globular stage, a zone of dividing cells was present in the centre of the embryo. c At the transitional stage, the scutellum $(s c)$ and coleorhiza $(\mathrm{col})$ were visible. A zone of dividing cells (ellipse) was located in the ventral-basal part of the embryo. d At the coleoptilar stage, the coleoptile (co), shoot meristem $(\mathrm{sm})$, scutellum $(\mathrm{sc})$, and coleorhiza $(\mathrm{col})$ were present. $d$ dorsal side of the embryo, $p$ protodermis, $v$ ventral side of the embryo, $z d c$ zone of dividing cells. Longitudinal sections through embryos stained with PAS + toluidine blue. Bars $=50 \mu \mathrm{m}$

cells with dense cytoplasm, small vacuoles, and nuclei in mitosis, was present (Fig. 1b).

At the transitional stage, apical-basal and ventral-dorsal polarization of the embryo was clearly visible. The protodermis covered the embryo, apart from the area which would give rise to the coleorhiza (Fig. 1c). The developing coleorhiza consisted of ground meristem cells with many starch grains. The outgrowth of a scutellum was also visible (Fig. 1c). It consisted of the ground meristem cells with large vacuoles. In ventral-basal directions, a zone of dividing cells was recognized (Fig. 1c). It will develop into the proper embryo, with the shoot meristem at the ventral/ apical side and the root meristem at the dorsal/basal side.

At the coleoptilar stage, a developing coleoptile and a shoot meristem as well as a developing scutellum and a root meristem with a coleorhiza, were observed (Fig. 1d; a root meristem is not visible on this section).
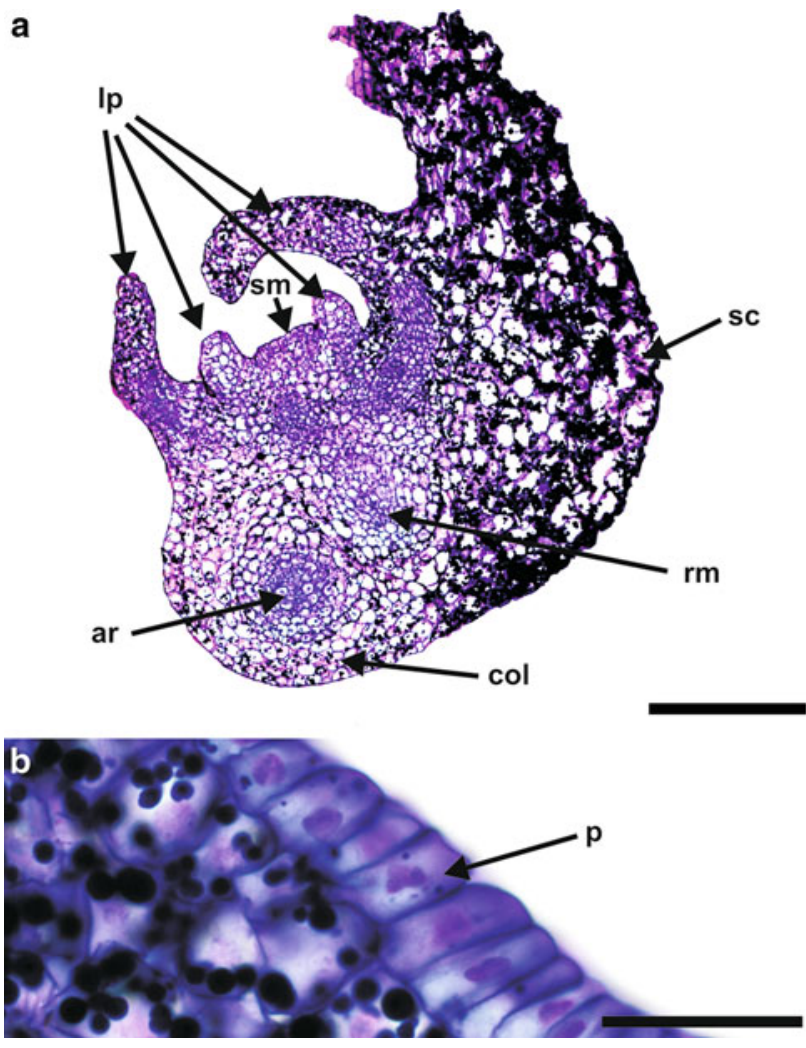

Fig. 2 Histology of a barley androgenic embryo at a mature stage of development. a At this stage, androgenic embryos consisted of a shoot and a root meristem, a coleorhiza, a scutellum and 4-6 leaf primordia. In addition to the main root, adventitious roots were also present. $\mathbf{b}$ The protodermis of the scutellum consisted of narrow cells. ar adventitious root, col coleorhiza, lp leaf primordia, $r m$ root meristem, sc scutellum, sm shoot meristem. Longitudinal sections through the embryo stained with PAS + toluidine blue. Bars $=$ $300 \mu \mathrm{m}$ (a), $30 \mu \mathrm{m}$ (b)

At the mature stage of development (Fig. 2a), the androgenic embryo consisted of a well-developed shoot axis/stem and a root meristem, a coleorhiza, a scutellum, a coleoptile (not visible in the section shown) and 4-6 leaf primordia. The shoot meristem consisted of tunica and corpus. The radicula was covered by a root cap and a rhizodermis was well developed. Underneath the rhizodermis, 2-3 cell layers of the ground tissue were present. The provascular tissue consisted of several layers of cells. Adventitious roots were also present (Fig. 2a). At a matured stage of development the radicle was separated from the coleorhiza (there was not any connection between the rhizodermis and cells of the coleorhiza (Suppl. Fig. S1 a).

The protodermis of the coleoptile consisted of narrow and elongated cells. The ground meristem in the coleoptile consisted of 5-6 layers of cells (counting from the protodermis to the provascular tissue) which were vacuolated and larger in size in comparison to the protodermis. The 
procambium of the coleoptile comprised 2-3 layers of narrow and elongated cells with dense cytoplasm. In the coleoptile the secondary-wall thickening in protoxylem tracheary elements was in the form of helical bars (data not shown). The leaf primordia were also well developed (Fig. 2a) and showed a protodermis under which the ground meristem and procambium were located. The scutellum was the most abundant part of the androgenic embryos (Fig. 2a). Its protodermal cells were elongated along anticlinal direction and formed a single layer of cells that were set close together (Fig. 2b).

Uncaged fluorescein distribution in androgenic embryos

\section{Analysis along the apical-basal axis}

At the very early globular stage, the fluorochrome was present in all embryo cells (Fig. 3a).

At the transitional stage, after uncaging of CMNB-caged fluorescein in the apical pole of the embryo, the fluorochrome was present in all cells of this pole and was absent in cells of the basal pole (Fig. 3b). This indicates that the embryo at the transitional stage could be divided into two symplasmic subdomains: apical and basal. The apical subdomain consisted of a scutellum and a developing shoot and root apical meristem and the basal subdomain contained a coleorhiza (all confirmed by histological analysis). In the apical subdomain, two areas with lower fluorescence were present to the left and right of the central axis (Fig. 3b). When the fluorochrome was uncaged in a few cells of the basal pole of the embryo, it became present in all cells of this pole but was always absent in cells of the apical pole (Fig. 3c).

At the coleoptilar stage and in mature androgenic embryos, after uncaging CMNB-caged fluorescein in a specific area of an embryo organ, fluorochrome was present in all cells of that organ but not in other cells of the embryo. For instance fluorochrome released into the coleorhiza (Fig. 3d) or SAM (Fig. 3e) was present only in cells of those organs. Thus, the SAM (with leaf primordia), radicle, coleoptile, scutellum and coleorhiza are isolated from each other (Suppl. Fig. S1 b-e).

\section{HPTS distribution in androgenic embryos}

\section{Analysis in the radial direction}

Embryos at the globular stage treated with HPTSA displayed three different patterns of symplasmic fluorescent tracer distribution. In the early globular stage, the fluorochrome was present in all embryo cells and fluorescence intensity was similar in each cell (Fig. 4a). In the older
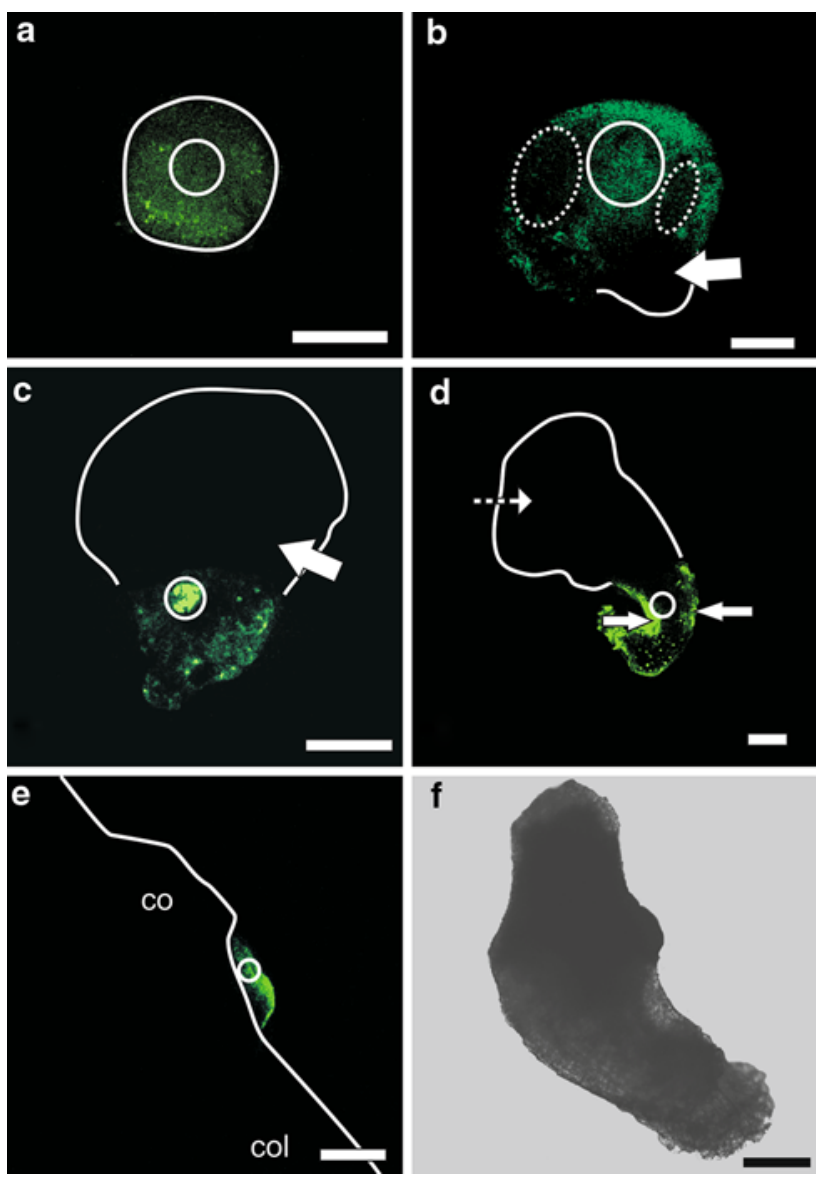

Fig. 3 Pattern of uncaged fluorescein distribution in barley androgenic embryos at different stages of development. a Fluorescein released into a few cells of the globular embryo has diffused into other cells of the embryo. b At the transitional stage, fluorescein was present in all cells of an apical pole after releasing the fluorochrome into some cells of this pole. Fluorescein was absent from the basal pole of the embryo (arrow). The intensity of fluorochrome fluorescence was lesser in a specific group of protodermal and underlying cells (dotted ellipsis) than in other cells of the apical pole. c At the transitional stage, after uncaging the fluorescein in a few cells of the basal pole, uncaged fluorescein was present in other cells of this pole but was absent in the cells of the apical pole (arrow). d At the coleoptilar stage, the fluorochrome was present in all cells of the coleorhiza after its release into a group of cells of this organ. The intensity of fluorescein fluorescence was the strongest in the protodermis (arrows). Fluorescein was absent in other organs such as scutellum (dashed arrow). e After uncaging of the caged fluorescein in a few cells of the embryonic shoot apical meristem at the coleoptilar stage, fluorescence was observed in other cells of the meristem. f Bright field image of the embryo whose SAM was shown in e. co coleoptile, col coleorhiza. White circle marks the area where CMNB-caged fluorescein was uncaged. White lines indicate the shape of the embryo as seen in bright field. Images were collected by confocal laser scanning microscopy. Bars $=100 \mu \mathrm{m}(\mathrm{a}-\mathrm{d}$ and $\mathrm{f})$, $50 \mu \mathrm{m}(\mathrm{e})$

globular stage, the fluorochrome was also present in all embryo cells but fluorescence intensity was greater in the centre of the embryo than in the peripheral/surface region (Fig. 4b). In embryos at the late globular, transitional, 

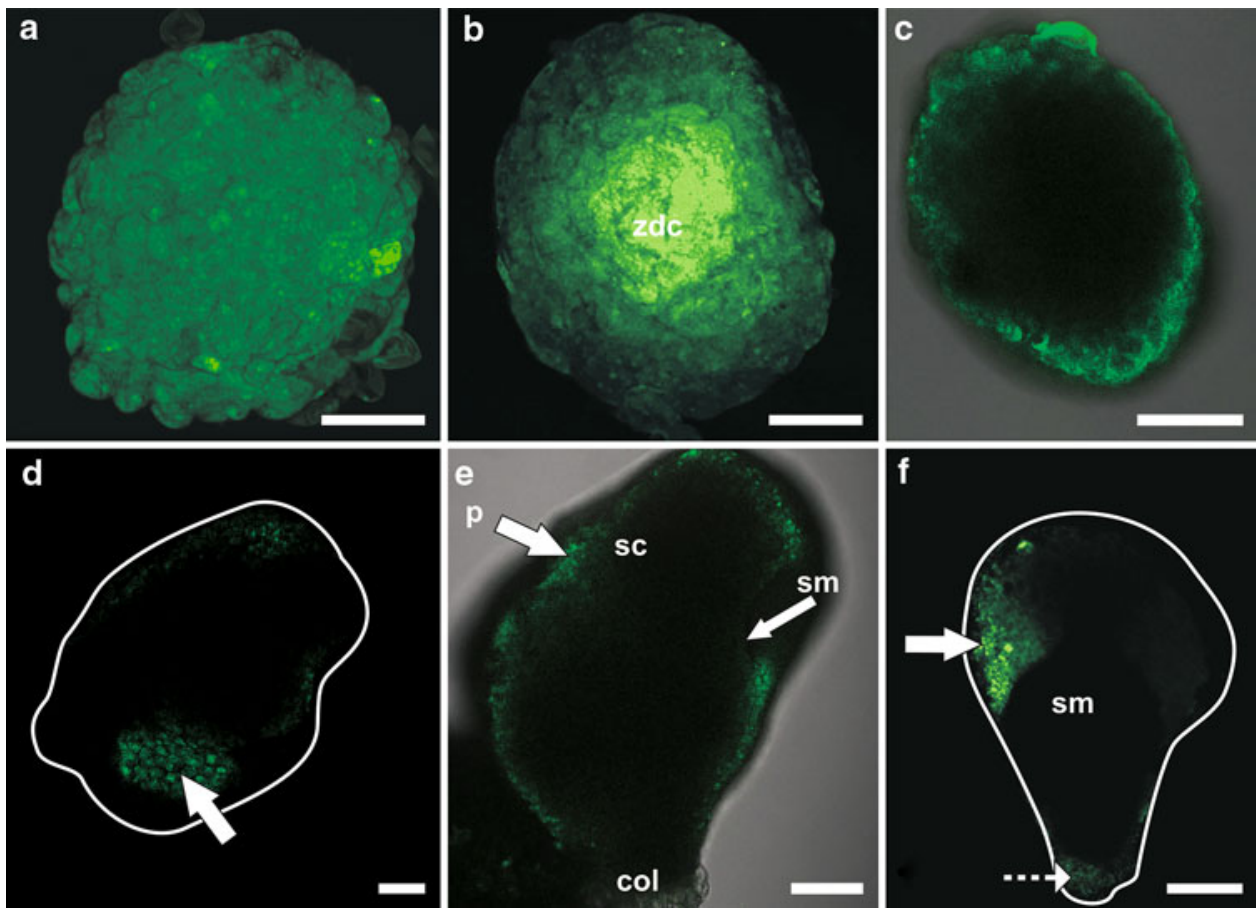

Fig. 4 Pattern of HPTS distribution in barley androgenic embryos at different stages of development. a In an embryo at the early globular stage, the fluorochrome was present in all embryonic cells. b A similar situation was observed for the globular stage, but the intensity of fluorescence was stronger in the centre of the embryo $(z d c)$. $\mathbf{c}$ At the late globular stage, the fluorochrome was present only in the protodermis. d-f This pattern of HPTS distribution was maintained at later stages of embryo development: transitional $(d)$, coleoptilar $(e)$,

coleoptilar and mature stage of development, the fluorochrome was present only in the protodermis (Fig. 4c-f).

\section{Discussion}

One objective of our study was to analyze the development of barley androgenic embryos in order to provide a context for the second part of our study, the defining of symplasmic (sub) domains during androgenesis. Morphological and histological analysis showed that (1) androgenic embryos pass through all developmental stages that are typical of zygotic embryos of grasses (Raghavan 1986), and (2) mature androgenic embryos possess all the same morphological and histological features as their zygotic counterparts (Bosnes et al. 1987).

Information on androgenesis in grasses is scarce, but morphology and organ arrangement of mature androgenic embryos of wheat (Indrianto et al. 2001) resemble that of barley. Development of nonzygotic barley embryos was previously studied morphologically and histologically only in somatic embryos derived from callus cells (Nonohay et al. 1999). Unlike our results, these studies showed that and mature $(f)$. The white lines indicate the shape of the embryos obtained from bright field micrographs. col coleorhiza, $p$ protodermis, $s c$ scutellum, sm shoot meristem, $z d c$ zone of dividing cells. Arrows point to protodermis. Dashed arrow points to a coleorhiza. Figure $4 \mathrm{c}$ and e show overlays of the images from fluorescence and bright field. The images were collected by confocal laser scanning microscopy. Bars $=50 \mu \mathrm{m}(\mathrm{a}, \mathrm{b}, \mathrm{d}), 100 \mu \mathrm{m}$ (c, e), $200 \mu \mathrm{m}$ (f)

the scutellum developed into a leafy structure and differentiation of the root system proceeded without the formation of embryogenic adventitious roots (Nonohay et al. 1999). Androgenic embryos differ from zygotic ones only in having a smaller size, as already described for monocot and dicot species (Nonohay et al. 1999). Taking these findings into consideration it might be suggested that, in the case of barley, androgenesis is more comparable to zygotic embryogenesis than it is to somatic embryogenesis.

In recent years, cell-to-cell communication has been postulated as an important factor controling plant growth, development and cell differentiation (Roberts and Oparka 2003; Zambryski 2004; Kim et al. 2005; Kobayashi et al. 2007; Tominga et al. 2008). In this intercellular communication, plasmodesmata are the key component because they participate not only in the transportation of solutes but also in the selective exchange of proteins, transcriptional factors, and ribonucleic acids (Wu et al. 2002; Kim and Zambryski 2005; Kobayashi et al. 2007).

During zygotic embryogenesis of Arabidopsis thaliana, development of symplasmic (sub) domains coincides with the radial and apical-basal differentiation of an embryo body (Kim et al. 2002; Kim and Zambryski 2005; Stadler 
et al. 2005). Distribution of symplasmic fluorochromes (HPTS and uncaged fluorescein) in the early globular stage of barley androgenic embryos suggests that, at this stage, the embryo is a single symplasmic unit where all cells are connected by functional plasmodesmata. It can be pointed out that such an interpretation is not correct if we take into consideration distribution of HPTS within embryos. We observed steady-state pattern of this fluorochome distribution within an embryo. It cannot be ruled out that HPTSA (non-fluorescent form) can penetrate cells inside the embryo via an apoplasmic rout and after uptake by inner embryo cells, further spread may occur symplasmically. However, determined distribution of the uncaged fluorescein within the embryo at this stage of development supports suggestion that there is no symplasmic barrier between embryo cells. A simple symplasmic domain was also shown for globular zygotic embryos of $A$. thaliana where no visible differences between embryonic cells were present (Kim et al. 2002; Kim and Zambryski 2005).

The first symplasmic subdomains of the barley androgenic embryo are visible in a late globular stage. These are an outer, the protodermis, subdomain and an inner subdomain which includes the underlying cells (Fig. 5a). In androgenesis, the differentiation of a protodermis must play a key role in embryo development since without a properly developed protodermis; androgenesis would probably be inhibited at the globular stage, as was shown for carrot embryos (de Jong et al. 1992). It is also possible that symplasmic isolation of the protodermis is necessary to maintain anticlinal cell divisions in this tissue (Considine and Knox 1981).

During zygotic embryogenesis of A. thaliana symplasmic subdomains are found along the apical-basal axis (Kim et al. 2005). These subdomains correspond to the sites of future embryonic organs, as shown by gene expression patterns (Kim et al. 2005). Symplasmic subdomains along the apical-basal axis of androgenic embryo also corresponded to embryo organs. At the transitional stage of androgenesis, the apical and basal poles were visible as separate symplasmic subdomains (Fig. 5b). This was probably the result of developmental changes which the embryo in that stage went through: outgrowth of the scutellum and the arising of the SAM and the radicula. Detection of two areas with lower fluorescence intensity in an apical subdomain at the transitional stage of androgenic embryos (Fig. 3b) is worth to discuss. On the basis of the location of these cells and histological analysis of the embryo (compare to Fig. 1c) in that stage, it can be concluded that these cells were the ones that built up a zone of dividing cells involved in creation of the embryo body and scutellum.

During further embryo development, new subdomains occurred which corresponded to embryo organs: the SAM

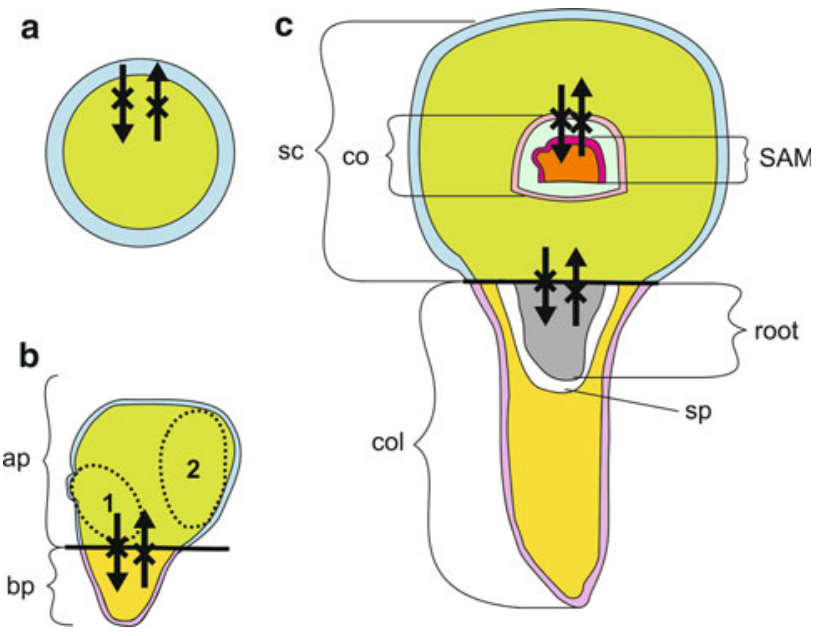

Fig. 5 Symplasmic subdomains in barley androgenic embryos. a At the late globular stage, two symplasmic subdomains were indicated: outer (the protodermis-blue) and inner (other cells of the embryogreen). b At the transitional stage, apical-outer (blue), apical-inner (green), basal-outer (purple), and basal-inner (yellow) symplasmic subdomains occur. Dotted ellipses indicate the embryo proper (1) and scutellum (2) subdomains. c At the coleoptilar and mature stage, symplasmic subdomains correspond to the scutellum, the coleoptile, the SAM (with leaf primordia at the mature stage), the radicle, and the coleorhiza. Moreover, in each subdomain (except the radicle) two other subdomains can be distinguished: outer and inner. Together, there are: outer and inner subdomains of the scutellum (blue and green, respectively), outer and inner subdomains of the coleoptile (pink and light blue, respectively), outer and inner subdomains of the SAM and leaf primordia (dark pink and orange, respectively), outer and inner subdomains of the coleorhiza (purple and yellow, respectively), and a single radicular subdomain (gray). Black lines indicate boundaries between the apical and basal poles of the embryos. Crossed arrows show that symplasmic movement does not occur between symplasmic subdomains. co coleoptile, col coleorhiza, SAM shoot apical meristem, $s c$ scutellum, $s p$ space between radicle and coleorhiza

with leaf primordia (the shoot axis), coleoptile, scutellum, radicle, coleorhiza (Fig. 5c). This further step in symplasmic isolation probably inhibits cell-to-cell signaling thus enabling cell differentiation and specific embryo organ formation.

Symplasmic subdomains within the androgenic embryo were proven with the use of only low-molecular symplasmic transport fluorochromes with molecular weights of about $0.5 \mathrm{kDa}$. Thus, the results indicate that the size exclusion limit (SEL) for plasmodesmata at the boundaries between symplasmic subdomains within the barley androgenic embryo is rather low. In the case of the zygotic embryo of Arabidopsis, low-molecular tracers can move through plasmodesmata at all developmental stages (Kim and Zambryski 2005). The average SEL value of plasmodesmata during normal plant development is about $1 \mathrm{kDa}$ (Zambryski and Crawford 2000). However, in some other examples SELs less than $1 \mathrm{kDa}$ were noticed (Erwee et al. 
1985; Rinne and van der Schoot 1998; Gisel et al. 1999; Stadler et al. 2005).

Symplasmic trafficking of small fluorescent molecules does not necessarily reflect the plasmodesmatal capacities in macromolecular transport (Itaya et al. 2002). The differences between transport of small and large molecules result from particular mechanism of transport. Small molecules diffuse from cell to cell via plasmodesmata (Crawford and Zambryski 2000; Liarzi and Epel 2005) whereas macromolecules are actively transported using portions of the cytoskeleton (Haywood et al. 2002; Oparka 2004). Some of macromolecules can also traverse the symplast by a diffusion-like process, an instance of which is the LEAFY transcriptional factor (Wu et al. 2003). Therefore, the obtained patterns of the fluorochrome distribution might also reflect patterns of macromolecular diffusion.

In conclusion, morphological and histological similarities between androgenesis and zygotic embryogenesis suggest that androgenesis can substitute for zygotic embryogenesis in experiments examining the regulatory mechanisms of the latter process. The observed correlation between symplasmic isolation and cell differentiation might suggest a similarity between zygotic and androgenic embryo development. If so, then symplasmic communication/isolation may be a universal mechanism controling cell differentiation, histogenesis and organogenesis during the plant development. Further studies should aim at elucidating the precise timing of symplasmic-domain occurrence during embryo development by analysing the distribution of symplasmic transport fluorochromes in barley mutants expressing cell type-specific markers.

Acknowledgments We thank Sławomir Samardakiewicz, Aleksander Ratajczyk and Marcin Kujawa for collecting data from the confocal laser scanning microscope and Ewa Mazur for preparing the series of sections of androgenic embryos. The authors are also grateful to anonymous reviewers for helpful comments on the manuscript.

Open Access This article is distributed under the terms of the Creative Commons Attribution Noncommercial License which permits any noncommercial use, distribution, and reproduction in any medium, provided the original author(s) and source are credited.

\section{References}

Bosnes M, Harris E, Aigeltinger L, Olsen O-A (1987) Morphology and ultrastructure of 11 barley shrunken endosperm mutants. Theor Appl Genet 74:177-187

Bugarova Z, Pret'ova A (1996) Isolated microspore cultures in Solanum tuberosum L. cultivars. Biologia 51:411-416

Chanana NP, Dhawan V, Bhojwani SS (2005) Morphogenesis in isolated microspore cultures of Brassica juncea. Plant Cell Tissue Org Cult 83:169-177
Considine JA, Knox RB (1981) Tissue origins, cell lineages and patterns of cell division in the developing dermal system of the fruit of Vitis vinifera L. Planta 151:403-412

Crawford KM, Zambryski PC (2000) Subcellular localization determines the availability of non-targeted proteins to plasmodesmatal transport. Curr Biol 10:1032-1040

Davies PA, Morton S (1998) A comparison of barley isolated microspore and anther culture and the influence of cell culture density. Plant Cell Rep 17:206-210

De Jong AJ, Cordewener J, Schiavo FL, Terzi M, Vandekerckhove J, van Kammen A, de Vries SC (1992) A carrot somatic embryo mutant is rescued by chitinase. Plant Cell 4:425-433

Duckett CM, Oparka KJ, Prior DAM, Dolan L, Roberts K (1994) Dye-coupling in the root epidermis of Arabidopsis is progressively reduced during development. Development 120:32473255

Erwee MG, Goodwin PB, Van Bel AJE (1985) Symplast domains in extrastelar tissues of Egeria densa Planch. Planta 163:9-19

Gisel A, Barella S, Hempel FD, Zambryski PC (1999) Temporal and spatial regulation of symplasmic trafficking during development in Arabidopsis thaliana apices. Development 126:1879-1889

Guha S, Maheshwari SC (1966) Cell division and differentiation of embryos in the pollen grains of Datura in vitro. Nature 212: 97-98

Haywood V, Kragler F, Lucas WJ (2002) Plasmodesmata: pathways for protein and ribonucleoprotein signaling. Plant Cell 14(Supplement):S303-S325

Indrianto A, Barinova I, Touraev A, Heberle-Bors E (2001) Tracking individual wheat microspores in vitro: identification of embryogenic microspores and body axis formation in the embryo. Planta 212:163-174

Itaya A, Ma F, Qi Y, Matsuda Y, Zhu Y, Liang G, Ding B (2002) Plasmodesma-mediated selective protein traffic between "symplasmically isolated" cells probed by a viral movement protein. Plant Cell 14:2071-2083

Kim I, Zambryski PC (2005) Cell-to-cell communication via plasmodesmata during Arabidopsis embryogenesis. Curr Opin Plant Biol 8:593-599

Kim I, Hempel FD, Sha K, Pfluger J, Zambryski PC (2002) Identification of a developmental transition in plasmodesmatal function during embryogenesis in Arabidopsis thaliana. Development 129:1261-1272

Kim I, Kobayashi K, Cho E, Zambryski PC (2005) Subdomains for transport via plasmodesmata corresponding to the apical-basal axis are established during Arabidopsis embryogenesis. Proc Natl Acad Sci USA 102:11945-11950

Kobayashi K, Otegui MS, Krishnakumar S, Mindrinos M, Zambryski P (2007) Increased size exclusion limit2 encodes a putative DEVH box RNA helicase involved in plasmodesmata function during Arabidopsis embryogenesis. Plant Cell 19:1885-1897

Konieczny R, Czaplicki AZ, Golczyk H, Przywara L (2003) Two pathways of plant regeneration in wheat anther culture. Plant Cell Tissue Org Cult 73:177-187

Liarzi O, Epel BL (2005) Development of a quantitative tool for measuring changes in the coefficient of conductivity of plasmodesmata induced by developmental, biotic, and abiotic signals. Protoplasma 225:67-76

Maraschin SF, Lamers GEM, de Pater BS, Spaink HP, Wang M (2003) 14-3-3 isoforms and pattern formation during barley microspore embryogenesis. J Exp Bot 54:1033-1043

Maraschin SF, Gaussand G, Pulido A, Olmedilla A, Lamers GEM, Korthout H, Spaik HP, Wang M (2005a) Programmed cell death during the transition from multicellular structures to globular embryos in barley androgenesis. Planta 221:459-470

Maraschin SF, Vennik M, Lamers GEM, Spaink HP, Wang M (2005b) Time-lapse tracking of barley androgenesis reveals 
position-determined cell death within pro-embryos. Planta 220:531-540

Martens HJ, Hansen M, Schulz A (2004) Caged probes: a novel tool in studying symplasmic transport in plant tissues. Protoplasma 223:63-66

Murashige T, Skoog FA (1962) A revised medium for rapid growth and bioassays with tobacco tissue cultures. Physiol Plant 15:437-497

Nonohay JS, Mariath JEA, Winge H (1999) Histological analysis of somatic embryogenesis in Brazilian cultivars of barley, Hordeum vulgare vulgare, Poaceae. Plant Cell Rep 18:929-934

Oparka KJ (2004) Getting the message across: how do plant cells exchange macromolecular complexes? Trends Plant Sci 9:33-41

Raghavan V (1986) Embryogenesis in angiosperms: a developmental and experimental study. Cambridge University Press, Cambridge, pp 15-35

Rinne PL, van der Schoot C (1998) Symplasmic fields in the tunica of the shoot apical meristem coordinate morphogenetic events. Development 125:1477-1485

Roberts AG, Oparka KJ (2003) Plasmodesmata and the control of symplastic transport. Plant Cell Env 26:103-124

Stadler R, Lauterbach Ch, Sauer N (2005) Cell-to-cell movement of green fluorescent protein reveals post-phloem transport in the outer integument and identifies symplastic domains in Arabidopsis seeds and embryos. Plant Physiol 139:701-712

Szarejko I (2003) Anther culture for doubled haploid production in barley (Hordeum vulgare L.). In: Maluszynski M, Kasha KJ, Forster BP, Szarejko I (eds) Doubled haploid production in crop plants. A manual. Kluwer Academic Publishers, Dordrecht, pp 35-42

Testillano PS, Ramirez C, Domenech J, Coronado M-J, Vergne P, Tatthys-Rochon E, Risueno MC (2002) Young microspore- derived maize embryos show two domains with defined features also present in zygotic embryogenesis. Int $\mathrm{J}$ Dev Biol 46:1035-1047

Tominga R, Iwata M, Sano R, Inoue K, Okada K, Wada T (2008) Arabidopsis CAPRICE-LIKE MYB 3 (CPL3) controls endoreduplication and flowering development in addition to trichome and root hair formation. Development 135:1335-1345

Vitha S, Baluska F, Mews M, Volkmann D (1997) Immunofluorescence detection of F-actin on low melting point wax sections from plant tissues. J Histochem Cytochem 45:89-96

Wang M, van Bergen S, van Duijn B (2000) Insights into a key developmental switch and its importance for efficient plant breeding. Plant Physiol 124:523-530

Wright KM, Oparka KJ (1996) The fluorescent probe HPTS as a phloem-mobile, symplastic tracer: an evaluation using confocal laser scanning microscopy. J Exp Bot 47:439-445

Wu X, Weigel D, Wigge PA (2002) Signaling in plants by intercellular RNA and protein movement. Genes Dev 16:151158

Wu X, Dinneny JR, Crawford KM, Rhee Y, Citovsky V, Zambryski PC, Weigel D (2003) Modes of intercellular transcription factor movement in the Arabidopsis apex. Dev 130:3735-3745

Zambryski PC (2004) Cell-to-cell transport of proteins and fluorescent tracers via plasmodesmata during plant development. J Cell Biol 162:165-168

Zambryski PC, Crawford K (2000) Plasmodesmata: gatekeepers for cell-to-cell transport of developmental signals in plants. Annu Rev Cell Dev Biol 16:393-421

Zimmermann R, Werr W (2005) Pattern formation in the monocot embryo as revealed by $N A M$ and $C U C 3$ orthologues from Zea mays L. Plant Mol Biol 58:669-685 